\title{
Actinomycotic Osteomyelitis of the Mandible: A Case Report
}

\author{
Young-Cheol Lee', Lee-Rang Lim¹', Kyu-Hoon Lee', Dong-Jun Seo', \\ $\mathrm{Na}-\mathrm{Ra}$ Yun ${ }^{2}, \mathrm{Ji}^{-S u} \mathrm{Oh}^{1}$, Jae-Seek You', ${ }^{1} \mathrm{Hae}-\mathrm{In} \mathrm{Choi}^{1}$ \\ 'Department of Oral and Maxillofacial Surgery, School of Dentistry, Chosun University, Gwangju, Korea \\ ${ }^{2}$ Division of Infectious Disease, Department of Internal Medicine, College of Medicine, Chosun University, Gwangju, Korea
}

Received August 13, 2019

Revised September 1, 2019

Accepted September 1, 2019

Correspondence to:

Hae-In Choi

Department of Oral and Maxillofacial

Surgery, School of Dentistry, Chosun

University, 309 Pilmun-daero, Dong-gu,

Gwangju 61452, Korea

Tel: +82-62-220-3810

Fax: +82-62-222-3810

E-mail: beautyluby@hanmail.net

https://orcid.org/0000-0002-2425-9506

This study was supported by research fund from Chosun University Dental Hospital, 2018.
Actinomycosis is rare, chronic, slowly progressive disease caused by gram-positive anaerobic organisms from the Actinomycosis family that normally colonizes the oral cavity. Actinomycotic osteomyelitis is even more rare and refractory disease because diagnosis by bacterial culture is not easy. In our case, 80-year-old man visited our clinic with a complaint of swelling and severe sinus tracts without teeth evolvement on anterior mandible. Computed tomography (CT) scan demonstrated erosive bone destruction on anterior mandible, clinically suspected actinomycotic osteomyelitis. The patient also had thoracic actinomycosis on Lt. lower lung. We could diagnosis actinomycosis by histopathologic examination. He treated by conservative surgery and long term antibiotics. After 2 year, no recurrence was seen in CT scan.

Key Words: Actinomycosis; Actinomycotic osteomyelitis

\section{INTRODUCTION}

Actinomycosis is rare chronic disease caused by Actinomyces spp. and once mistaken for fungal infection [1]. Actinomyces spp. is Gram-positive anaerobic bacteria, including Actinomycosis israelii, A. bovis, A. odontolyticus, and $A$. viscus. They can be found in calculus, gingival crevices, infected dentin and commonly live in pharynx and tonsil [2]. Actinomyces has no pathogenic potential when exposed to normal skin or healthy mucosa. Once losing membrane continuity by trauma or dental surgery, Actinomyces can invade into mucous membrane and form localized abscess [3].

Actinomycosis can be divided in three categories: cervicofacial (55\%), abdominopelvic (20\%), thoracic (15\%) depending on the region [4]. Cervicofacial actinomycosis is the most common type; it can spread in acute form to hypopharynx, larynx, lacrimal duct and gland, major salivary gland, oral mucous, mandible, paranasal sinus and scalp; it can be chronic condition forming granuloma or multiple sinus tract and fistula [5]. Periapical actinomycosis, less invasive subtype of cervicofacial actinomycosis, has been reported, too [6].

Pus culture and bacterial examination is needed for diagnosis. Culture of Actinomyces spp. require specific oxidation-reduction condition associated with microbiome. In clinic, diagnosis of actinomycosis can be difficult even in highly suspected. Several months of antibiotics are required of treating actinomycosis and it can recur if treatment is stopped early. Making early definite diagnosis is important for preventing recurrence of actinomycosis [7].

There are few case reports of actinomycosis and even much rare case reports of osteomyelitis by Actinomyces except for medication related osteonecrosis of jaw. This report is about a

Copyright (c) 2019 Korean Academy of Orofacial Pain and Oral Medicine. All rights reserved.

(c) This is an open-access article distributed under the terms of the Creative Commons Attribution Non-Commercial License (http://creativecommons.org/licenses/by-nc/4.0/), which permits unrestricted non-commercial use, distribution, and reproduction in any medium, provided the original work is properly cited. 
case of 80-year-old man with actinomycotic mandibular osteomyelitis, which is identified later to co-infection of cervicofacial and thoracic type.

\section{CASE REPORT}

A 80-year-old man presented with mandibular incisor pain and swelling. Pain has been for 20 days and there was no surgery, trauma history and no underlying systemic disease. In physical examination, right cervical lymph node enlargement and multiple fistula in mandibular lateral incisor, canine, first premolar and first molar were observed. Elective pulp test on those teeth were all positive and no suspected teeth involvement was observed in panorama (Fig. 1) and periapical view. Clinically, actinomycosis was suspected and pus culture and bacterial examination were held but failed to culture actinomyces. Computed tomography (CT) and biopsy were perfomed for diagnosis. Irregular destruction on mandibular incisor labial bone was observed in CT (Fig. 2) and histological examination

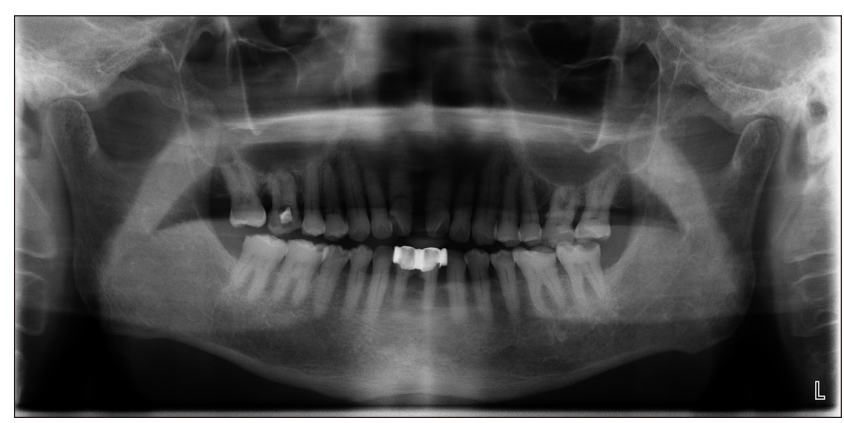

Fig. 1. First visit panoramic view. confirmed actinomycotic osteomyelits. Patient was admitted to the emergency room presenting with severe swelling on right lower face, pain and limited mouth opening during administration of prescribed amoxicillin under cooperating with divsion of infectious diseases. In enhanced neck computed tomoraphy, there was abscess pocket showing irregualr constract enhancement in right submasseteric space and pterygomandibular space (Fig. 3). drainage on pus pocket and curettage of bone on incisor area were performed under local anesthesia.

Meanwhile, chest compute tomography was performed as routine ward laboratory examination despite of no symptom, observing tuberculosis-like lesion in left lower lobe in chest X-ray (Fig. 4A). Considering patient's history,

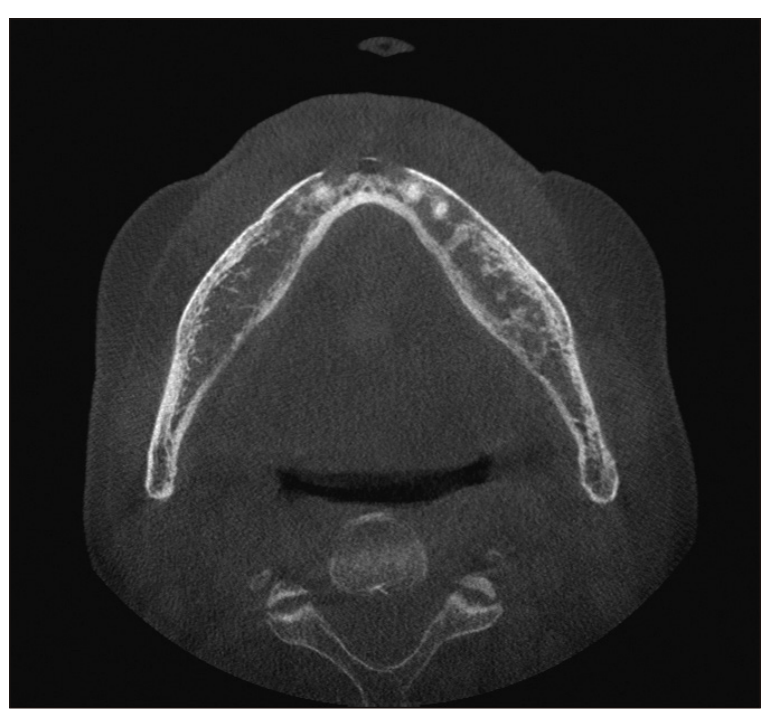

Fig. 2. First visit computed tomography. Anterior mandibular labial bone resorption was observed.

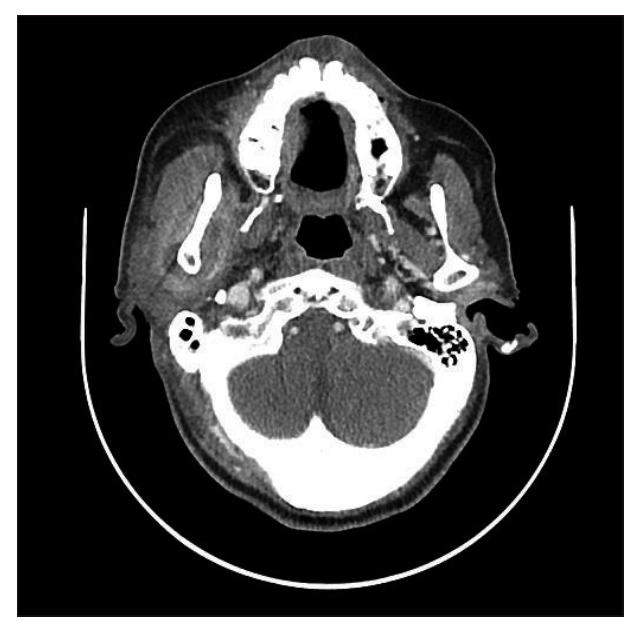

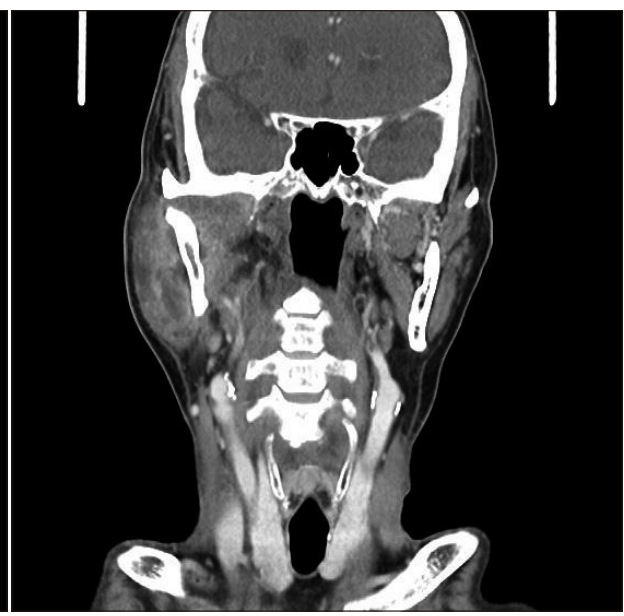

Fig. 3. Irregular contrast enhancement was observed in right submassteric and pterygomandibular space. 

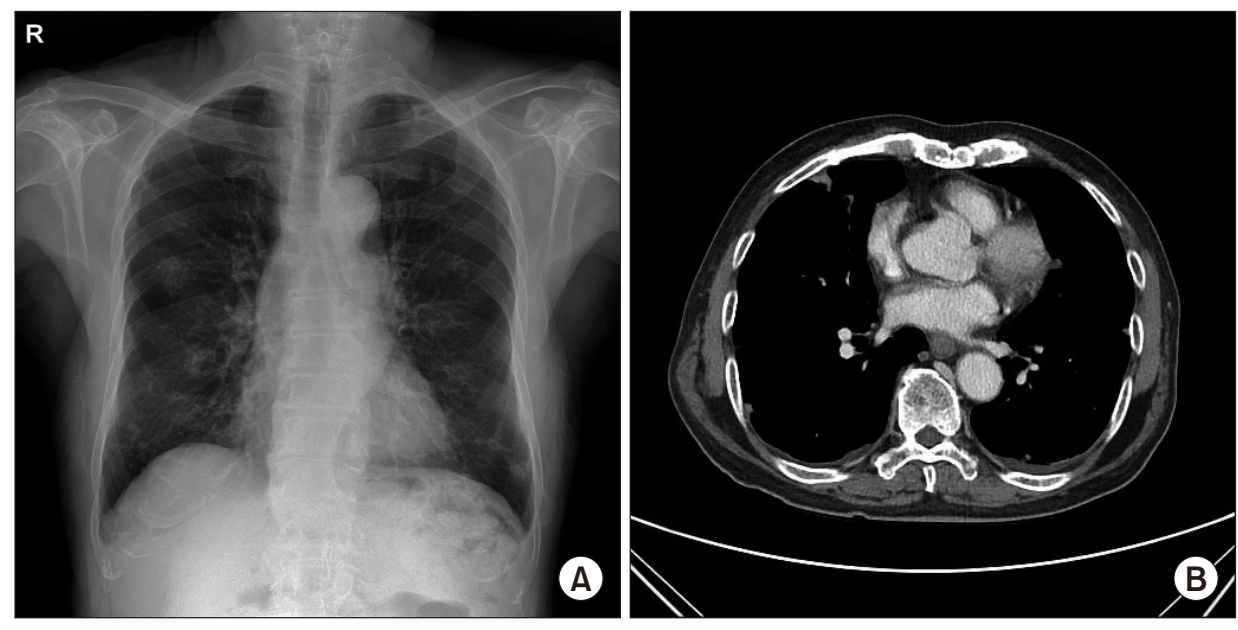

Fig. 4. (A) A pathogen similar to tuberculosis is seen in the left and lower lobe of the chest radiography. (B) Mild abscess and sclerosis are seen in chest computed tomography. disseminated actinomycosis was suspected, left lower lobectomy was performed under general anesthesia in department of cardiothoracic surgery. It was finally confirmed actinomycosis by histopathologic examination. Patient was prescribed doxycycline over 10 months after discharge. After 2 years, patient visited for another reason with no sign of recurrence of actinomycosis. CT showed healing state of mandibular bone (Fig. 5).

\section{DISCUSSION}

After first reporting of actinomycosis, misunderstood to fungal infection in 1845 by Van Langenbeck, Bollinger et al. assumed that Actinomyces bovis were fungus breaking out 'lumpy jaw' in cow. Wolff et al. succeeded in isolation culture from human body in 1891 and Waksman concluded that Actinomyces are Gram-positive anerobic bactera, not fungus in 1960s [8].

Cervicofacial actinomycosis is usually associated with soft tissue of chin and neck area and make multiple fistula on skin with swelling. It is characterized by features that infection spreads ignoring anatomical plane. Infected skin has abscess with purplish red and indurated, wood-like area. Special sulfur granule is observed in fistula drainage. Since another fistula appears when the former fistula disappears, extensive scarring and facial deformity in prolonged duration of untreated patient with actinomycosis.

Actinomycotic osteomyelitis is rare, which accounts for about $12 \%$ of total osteomyelitis [9]. Cervicofacial actinomycotic osteomyelitis usually occurs in mandibular body,

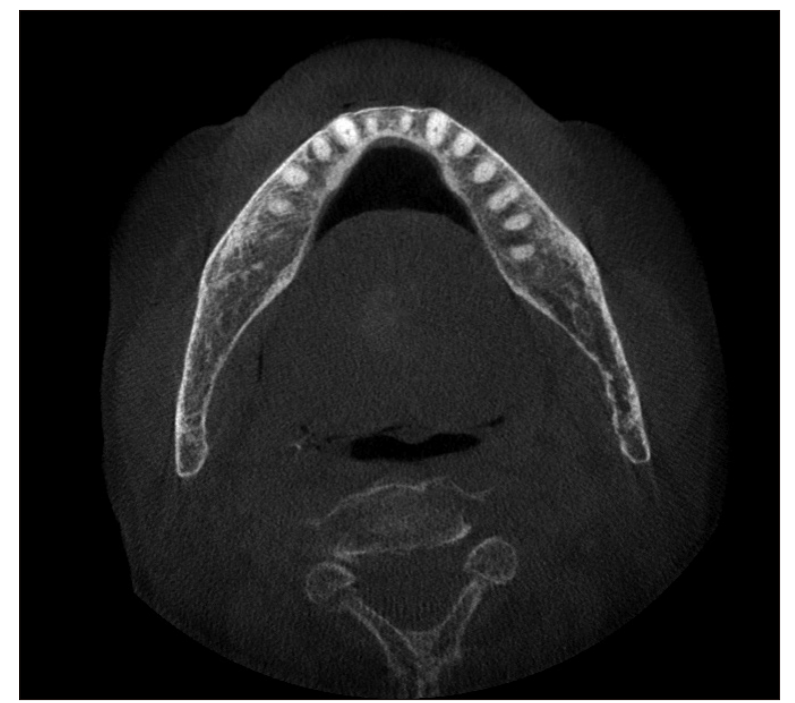

Fig. 5. A 2 year follow-up computed tomography view. Healing state at anterior mandible area.

following symphysis, ramus, mandibular angle. Maxilla and temporomandibular joint are comparatively resistant for the disease and prevalence is a ratio mandible:maxilla of $4: 1$. It is assumed that mandible is more commonly affected than maxilla due to the lesser vascularity and the denser cortical bone, similar to osteoradionecrosis [10]. In this case, coinfection of cervicofacial and thoracic type was shown by invasion of symphysis and lung.

Actinomyces in oral flora in patient with poor oral hygiene could be inhaled to lung through the pharynx. It could be cause of thoracic actinomycosis. Thoracic actinomycosis forms micro-abscess and focal consolidation in parenchyma, fibrosis of local tissue. It was shown like tuberculosis, infiltration, malignancy in chest PA [11]. Thoracic 
actinomycosis cannot be diagnosed without surgical intervention, while cervicofacial actinomycosis can be treated by removal of fistula and long-term antibiotics. Biopsy is required to rule out pulmonary malignancy especially [12].

In this case, thoracic type actinomycosis was likely to occur because of long-time untreated condition and inhalation of abscess with poor oral hygiene due to mouth opening limitation because of abscess pocket of masticator space. To prevent thoracic actinomycosis, meticulous oral hygiene is essential in cervicofacial actinomycosis patient.

Pathophysiology of actinomycotic osteomyelitis has not clearly defined yet. Actinomyces can be found in tonsil, sulcus fluid, mucus membrane, infected dentin and tooth extrated area but cannot be infectious by itself. Actinomycotic osteomyelitis may be shown in the circumstance with broken balance of normal flora and pathologic change by chronic inflammation for some reason. Actinomyces itself is less invasive and toxic than other pathogens. Another bacteria help actinomyces to invade tissue with production of toxin and enzyme. These polymicrobial conditions make proper environment for growing anaerobic bacteria having low oxido-reduction potential [13]. Not forming sulfur granule of actinomyces in laboratory environment, it suggests that invasion of host immune system and colonization of associated bacteria are cornerstones to actinomycosis [14]. Once infection established on bone, the host makes inflammation response, suppuration, forming granuloma, fibrosis and making fistula.

Actinomycosis is shown clinically like tuberculosis and granuloma mimicking malignant lesion. Actinomycotic osteomyelitis usually proceeds slowly, but there were severe cases that infection invaded to mid-face, skull base, and cranium [15], and that proceed so rapidly that mandible was fractured, requiring reconstruction in immunosuppressive patient [16]. It is very important to diagnose actinomycosis, but it is reported that usual bacterial examination can confirm actinomycosis in less than 50\% and first visit examination in less than 10\% [17]. Four case series of actinomycotic osteomyelitis of Sezer et al. [18] reported to fail to make definite diagnosis of actinomycosis by usual microbiological examination. If the examination are failed repeatedly and delayed, it can get more inaccurate by effect of antibiotics. In this case, biopsy is highly recommended for diagnosis [19]. Actinomyces are strongly stained by H\&E and Periodic acid-Schiff, Giemsa (GMS), especially filaments are well-shown in GMS [20].

In this case, there was no collection of actinomyces in first test. After several test, penicillin-resistant Streptococcus pneumonia, S. parsanguinis, candida was found but not found actinomyces at all. Definite diagnosis is performed by biopsy of mandible and lung. When actinomycosis is highly suspected clinically, biopsy helps more accurate diagnosis, as well as scrutinizing microbiological test.

It can be treated long-term antibiotic application in case of cervicofacial actinomyces localized in soft tissue, but when osteomyelitis is accompanied as this case, surgical intervention is essential. If acute abscess formation and necrotic tissue exists, surgical treatment is also required to distribute antibiotics more effectively. Antibiotic treatment for actinomycosis usually consists of 2-6 weeks of penicillin antibiotics by intravenous injection and 2-12 months of amoxicillin oral administration after IV [21]. Tetracyclin, minocycline, erythromycin, cephalosporin, sulfonamide, streptomycin can be used If patient has allergy for penicillin. In case of penicillin-resistant bacteria, clindamycin can be used by oral administration [22]. In this case, penicillinresistant $S$. pneumonia, $S$. parsanguinis is detected, ceftriaxone and vancomycin was prescribed intravenously. Doxycycline was also prescribed through oral administration over 10 months after discharge.

In conclusion, early and thorough diagnosis, appropriate surgery, long-term administration of antibiotics is required for actinomycotic osteomyelitis. When actinomycosis is clinically suspected, biopsy is recommended that cannot be diagnosed by typical microbiological culture test.

\section{CONFLICT OF INTEREST}

No potential conflict of interest relevant to this article was reported.

\section{ORCID}

\author{
Young-Cheol Lee \\ https://orcid.org/0000-0001-6371-7445 \\ Lee-Rang Lim
}


https://orcid.org/0000-0001-6751-9091

Kyu-Hoon Lee

https://orcid.org/0000-0002-0236-1788

Dong-Jun Seo

https://orcid.org/0000-0002-4301-5881

Na-Ra Yun

https://orcid.org/0000-0002-4219-0127

Ji-Su Oh

https://orcid.org/0000-0002-8369-5025

Jae-Seek You

https://orcid.org/0000-0001-7638-9583

Hae-In Choi

https://orcid.org/0000-0002-2425-9506

\section{REFERENCES}

1. Benoliel R, Asquith J. Actinomycosis of the jaws. 2 Case reports. Int J Oral Surg 1985;14:195-199.

2. Laskaris G. Oral manifestations of infectious diseases. Dent Clin North Am 1996;40:395-423.

3. Miller M, Haddad AJ. Cervicofacial actinomycosis. Oral Surg Oral Med Oral Pathol Oral Radiol Endod 1998;85:496-508.

4. Brown JR. Human actinomycosis. A study of 181 subjects. Hum Pathol 1973;4:319-330.

5. Nagler R, Peled M, Laufer D. Cervicofacial actinomycosis: a diagnostic challenge. Oral Surg Oral Med Oral Pathol Oral Radiol Endod 1997;83:652-656.

6. Hirshberg A, Tsesis I, Metzger Z, Kaplan I. Periapical actinomycosis: a clinicopathologic study. Oral Surg Oral Med Oral Pathol Oral Radiol Endod 2003;95:614-620.

7. Kaplan I, Anavi K, Anavi Y, et al. The clinical spectrum of Actinomyces-associated lesions of the oral mucosa and jawbones: correlations with histomorphometric analysis. Oral Surg Oral Med Oral Pathol Oral Radiol Endod 2009;108:738-746.

8. Bala S, Narwal A, Gupta V, Duhan J, Goel P. Actinomycotic osteomyelitis of mandible masquerading periapical pathology. $\mathrm{J}$ Oral Health Community Dent 2011;5:97-99.
9. Acevedo F, Baudrand R, Letelier LM, Gaete P. Actinomycosis: a great pretender. Case reports of unusual presentations and a review of the literature. Int J Infect Dis 2008;12:358-362.

10. Figueiredo LM, Trindade SC, Sarmento VA, de Oliveira TF, Muniz WR, Valente RO. Actinomycotic osteomyelitis of the mandible: an unusual case. Oral Maxillofac Surg 2013;17:299-302.

11. Endo S, Murayama F, Yamaguchi T, et al. Surgical considerations for pulmonary actinomycosis. Ann Thorac Surg 2002;74:185190.

12. Taştepe AI, Ulaşan NG, Liman ST, Demircan S, Uzar A. Thoracic actinomycosis. Eur J Cardiothorac Surg 1998;14:578-583.

13. Gannepalli A, Ayinampudi BK, Baghirath PV, Reddy GV. Actinomycotic osteomyelitis of maxilla presenting as oroantral fistula: a rare case report. Case Rep Dent 2015;2015:689240.

14. Marx RE, Carlson ER, Smith BR, Toraya N. Isolation of Actinomyces species and Eikenella corrodens from patients with chronic diffuse sclerosing osteomyelitis. J Oral Maxillofac Surg 1994;52:26-33; discussion 33-34.

15. Shen JY, Futran ND, Sardesai MG. Craniofacial Actinomyces osteomyelitis evolving from sinusitis. Radiol Case Rep 2017;13:104107.

16. Kusuyama Y, Matsumoto K, Okada S, Wakabayashi K, Takeuchi N, Yura Y. Rapidly progressing osteomyelitis of the mandible. Case Rep Dent 2013;2013:249615.

17. Abbaszadeh H, Sheibani MS. Actinomycotic osteomyelitis of mandible. J Craniofac Surg 2016;27:e452-e454.

18. Sezer B, Akdeniz BG, Günbay S, Hilmioğlu-Polat S, Başdemir G. Actinomycosis osteomyelitis of the jaws: report of four cases and a review of the literature. J Dent Sci 2017;12:301-307.

19. Goldstein BH, Sciubba JJ, Laskin DM. Actinomycosis of the maxilla: review of literature and report of case. J Oral Surg 1972;30:362-366.

20. Chandler FW, Watts JC. Fungal diseases. In: Anderson WAD, Damjanov I, Linder J, eds. Anderson's pathology. 10th ed. St. Louis: Mosby; 1996. pp. 951-982.

21. Bennhoff DF. Actinomycosis: diagnostic and therapeutic considerations and a review of 32 cases. Laryngoscope 1984;94:11981217.

22. Dubey A, Murthy JG, Banerjee PK. Actinomycosis of the parotid gland. Indian J Otolaryngol Head Neck Surg 2004;56:306-308. 